This is the post-peer reviewed final draft version of the following article: Heeks, R. \& Hawari, A. "Explaining ERP Failure in a Developing Country: A Jordanian Case Study", Journal of Enterprise Information Management, 23(2), 135-160, 2010, which has been published in final form at:

http://www.emeraldinsight.com/journals.htm?articleid=1839086

\title{
Explaining ERP Failure in a Developing Country: A Jordanian Case Study
}

\author{
Ala'a Hawari \& Richard Heeks* \\ Centre for Development Informatics, University of Manchester, UK
}

* Corresponding author:

Prof. Richard Heeks, CDI, IDPM, Arthur Lewis Building, University of Manchester, Manchester, M13 9PL, UK +44-161-275-2870. Email:

richard.heeks@manchester.ac.uk

\begin{abstract}
Purpose - Enterprise resource planning (ERP) systems are increasingly being adopted by organisations in developing countries. As in industrialised countries, this adoption seems beset by significant rates of failure, leading to a large waste of investment and other resources. This study seeks to understand why such ERP failure occurs.
\end{abstract}

Design/methodology/approach - This study moves beyond factor lists to make use of an overall "design - reality gap" model. The model is applied to a case study of ERP failure in a Jordanian manufacturing firm, analysing the situation both before and during ERP implementation through a mix of interviews, observation and document analysis.

Findings - The research finds sizeable gaps between the assumptions and requirements built into ERP system design, and the actual realities of the client organisation. It is these gaps - and the failure to close them during implementation that underlie ERP project failure.

Research limitations/implications - This study shows the relevance and applicability of the design - reality gap model to understanding ERP failure. Further research can be undertaken applying the model to other ERP cases, including case studies of success.

Practical implications - The paper draws conclusions about good practice in ERP implementation relating to both risk identification and risk mitigation, which must be based on closing design - reality gaps. It offers examples of both specific and generic actions that help to achieve this. But it also notes limitations existing in some developing country contexts that may continue to constrain the effective use of enterprise resource planning systems. 
Originality/value - This study provides a new model for understanding ERP project success and failure, and for practical risk mitigation. The design - reality gap model aims to be comprehensive but also contingent; sensitive to the specific conditions of any individual client organisation.

Keywords enterprise resource planning, developing countries, IS failure

Paper type Research paper 


\section{Introduction to ERP}

Enterprise resource planning (ERP) can be defined as "a software system with integrated functions for all major business functions across an organization such as production, distribution, sales, finance, and human resources management. A single package typically replaces many different previous packages" (Bocij et al 2003: 47). The intention is that an ERP system provides a single locus for real-time access to virtually all significant organisational data that only has to be entered once into the system (Minahan 1998).

ERP is intended to deliver a significant improvement over the non-holistic nature of earlier organisational information systems. There are therefore reports of ERP systems providing benefits such as cost reductions, improved productivity, better managerial decision-making, and facilitation of process or structural change (Shang \& Seddon 2000; Barki \& Pinsonneault 2002; Kamhawi 2008; Federici 2009).

However, there are also frequent reports of ERP failure:

- "many ERP systems still face resistance, and ultimately, failure" (Aladwani 2001:266)

- $\quad$ "between 50 percent and 75 percent of U.S. firms experience some degree of failure ... One recent survey revealed that 65 percent of executives believe ERP implementation has at least a moderate chance of hurting their business." (Umble \& Umble 2002:26)

- $\quad$ "three quarters of the ERP projects are considered failures and many ERP projects ended catastrophically" (Rasmy et al 2005:1)

- "failure rates estimated to be as high as 50\% of all ERP implementations" (Muscatello \& Parente 2006:61)

- $\quad$ "70 percent of ERP implementations fail to deliver anticipated benefits" (Wang et al 2007:200).

These reports are drawn from industrialised country settings. ERP take-up has been much lower in developing countries (DCs), with estimates that these countries make up some 10-15\% of global ERP sales (Huang \& Palvia 2001; Rajapakse \& Seddon 2005a). However, developing countries look set to become the locus for a major expansion of ERP implementations (Molla \& Bhalla 2006). Yet, at the same time, reports have emerged of ERP failures in these countries (e.g. Al-Mashiri \& Zairi 2000; Rajapakse \& Seddon 2005b) including suggestions that developing country implementations face specific difficulties over and above those found in industrialised countries (Xue et al 2005; Kamhawi 2007; Soja 2008).

On the basis of this background - the growing investment in, and potential of, ERP systems in developing countries combined with high rates of failure but relatively little literature on ERP experiences in DCs (Molla \& Bhalla 2006) - this paper sets out in general terms to address the question of why ERP projects might fail in a developing country. Following an explanation of the research approach and conceptual models used, it outlines a case study of ERP failure in one developing country. This is then analysed using a new conceptual framework, looking at risk factors both before and after system implementation. On the basis of this model, some recommendations can be made for trying to move on from failure, or avoid it in 
other situations using the model as an analytical tool, though these may be difficult to achieve given the constraints that exist in certain developing country contexts. In the final section, conclusions are drawn about the value and practical and research implications of the new model.

\section{Research Frameworks, Focus and Method}

This paper adopts a case study approach, focusing on an ERP project in Jordan. Jordan was selected as a typical developing country location for ERP implementation. Like many DCs, it has become a target for major ERP vendors looking for new sales growth locations (Sbool 2006). At the same time, ERP implementation projects in Jordan face problems and, in many cases, these projects can be classified as failures (ibid).

Our research therefore focused on two main questions:

- How can the outcome of an ERP project be classified as a success or failure?

- How can we understand why that ERP project outcome occurred?

In addressing the first question, of outcome classification, a number of earlier ERP studies provide no clear basis for their assessment of success or failure. Of those that do, we can adapt Kamhawi (2008) by identifying three approaches to outcome classification: focus on project process such as whether the ERP project is delivered on time and on cost (e.g. Al-Mashari \& Zairi 2000; Hong \& Kim 2002); focus on organisational impact such as savings in staff time/cost, or improvements in decision quality (e.g. Umble \& Umble 2002; Wang et al 2007); and focus on user satisfaction (e.g. Zhang et al 2002; Wu \& Wang 2007). A number of studies combine the first two approaches but our interest in answering our first question was in outcome, not process. We therefore looked for a way to combine the second two approaches.

One way to do this was to use DeLone and McLean's (1992) model of information systems (IS) success. Although mentioned by a number of the ERP studies in our review (e.g. Rasmy et al 2005; Xue et al 2005) this model had not been systematically applied. Yet not only does it provide a way to combine the two key outcome measures used in earlier ERP studies; it provides a more comprehensive picture of ERP success and failure by incorporating six outcome elements in all, as summarised in Figure 1:

- System quality relates to the desired features and characteristics of the information system itself.

- Information quality concerns the characteristics of the information produced by the system.

- Use and user satisfaction are concerned with the interaction between the information produced by the system and the recipients.

- Individual impact relates to the extent to which the information produced by the system influences or affects management decisions.

- Organisational impact measures the effect of the information produced by the system on organisational performance. 
Figure 1: Model of Information Systems/ERP Success

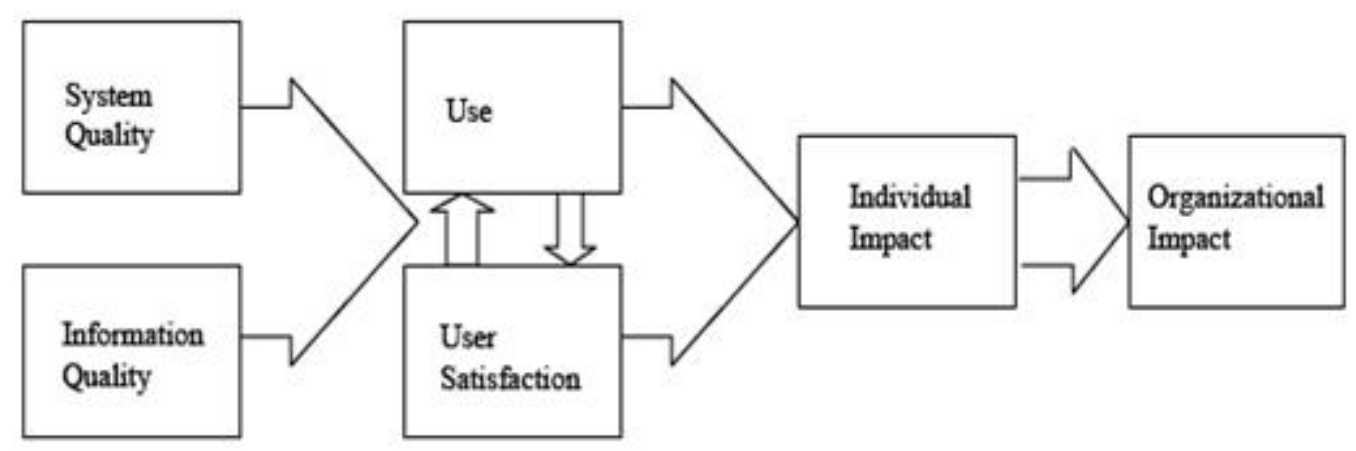

Source: DeLone \& McLean (1992)

This model could answer our first question by helping to evaluate and classify ERP success or failure. But we also wished to understand why the particular outcome (argued in this case to be failure) occurred. To address this second question, we drew together two different strands of thinking.

We drew in part from the literature on IS success and failure. The general literature on IS failure (e.g. Lyytinen \& Hirschheim 1987; Horton \& Lewis 1991) and the specific literature on IS failure in developing countries (e.g. Boon 1992; Beeharry \& Schneider 1996) has been helpful in building knowledge. However, there have been criticisms that such literature has been poor at explaining the causes of failure, and poor at taking account of the differing contexts in which information systems are implemented (Sauer 1993; Poulymenakou \& Holmes 1996, Montealegre 1999).

The IS failure literature has therefore developed more contingent ideas that seek to explain the causes of IS failure. Central to a number of these has been the notion of "fit": the idea that IS success and failure is determined by some degree of match or mismatch. This has been interpreted in a number of different ways, which could have been used as the basis for our model. One line of work deriving from Leavitt (1965) seeks to understand the fit between different IS factors, such as between processes, people, structure and technology (e.g. Venkatraman 1989). Another seeks to understand the fit between different stakeholder groups: their assumptions and expectations (e.g. Orlikowski \& Gash 1994).

A third - the one developed here - focuses on the fit between the information systems design and the organisational setting into which that system is being introduced (Markus \& Robey 1983; Pliskin et al 1993). Together, these authors identify five dimensions on which this fit may occur: user competencies, organisational structure, organisational politics, organisational culture, and broader contextual factors. Their ideas can be understood through the notion of inscription: the idea that system designers inscribe into information systems a "vision of (or prediction about) the world" which draws from the designers' worldview, but which may mismatch the realities of the organisation in which the system is implemented (Akrich 1992:208; also Suchman 1987). 
The second strand of thinking from which we drew to develop such a model was the ERP literature; particularly that on failure of ERP in developing countries. Some of this has explained failure simply in terms of a set of factors such as: lack of skills and technology, absence of good quality data, lack of money, user resistance, and cultural issues (e.g. Wong et al 2004; Rajapakse \& Seddon 2005a; Rasmy et al 2005; Xue et al 2005; Kamhawi 2008; Soja 2008). We wished to avoid a simple "list of factors" approach because of the identified need for a contingent approach to ERP that recognises different implementation issues in different settings (e.g. García-Sánchez \& Pérez-Bernal 2007).

Of more relevance, then, were those earlier ERP studies that - paralleling ideas in the IS failure literature - promoted the contingent notion of fit. In the ERP literature, this has generally followed the "third approach" identified in the IS failure literature; described in terms of a fit between the ERP system and the client organisation (e.g. Hong \& Kim 2002). Developing country case studies most frequently seem to discuss this in terms of a fit of culture (e.g. Zhang et al 2002; Rajapakse \& Seddon 2005b; Xue et al 2005; Molla \& Bhalla 2006). (Indeed, such is the linkage made between ERP and culture that we will return to it in more detail in our discussion.) Other studies, though, extend the notion of fit between system and client organisation beyond just culture. They include fit of data, processes and user interface (Hong \& Kim 2002) and fit of objectives, technology and strategy (Kamhawi 2007).

Drawing the two strands together, we sought to create a model for understanding ERP success and failure that was fundamentally about the fit between system design and the realities of the organisational context into which that system was being introduced. The foundation of the model, then, is expressed in simple terms as the "design - reality gap": the degree of fit between, on the one hand, the requirements and assumptions built into the information system design and, on the other, the real situation found in the organisational context of implementation. On the basis of the earlier IS failure and ERP literature, we propose that the larger this design-reality gap, the greater the risk of IS failure. Equally, the smaller the gap, the greater the chance of success.

To make the model systematic, it would need to integrate the various factors from earlier literature. This would include not just the literature explicitly discussing fit because we recognised that the factors cited to explain ERP success and failure in developing countries could be understood in terms of fit. Lack of skills, absence of good quality data, user resistance and so forth could all be represented as a lack of fit between what ERP system implementation required and what the client organisation had available. We therefore sought a model that could encompass a multi-factoral notion of fit between system design requirements and actual organisational availability.

Analysis of the ERP literature cited above and other information systems project research (e.g. Heeks 2002) indicated that seven dimensions - summarised by the ITPOSMO acronym - are necessary and sufficient to provide a comprehensive understanding of design - reality gaps:

- Information (data stores, data flows, etc.)

- Technology (both hardware and software)

- Processes (the activities of users and others) 


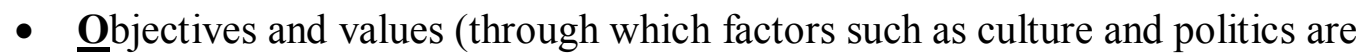
manifest)

- Staffing and skills (both the quantitative and qualitative aspects of competencies)

- Management systems and structures

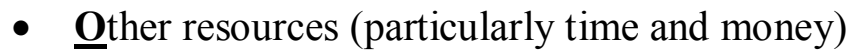

Putting these dimensions together with the notion of gaps produces the model for understanding success and failure of information systems, including ERP, that is shown in Figure 2.

Figure 2: The Design—Reality Gap Model for Analysing IS Success and Failure
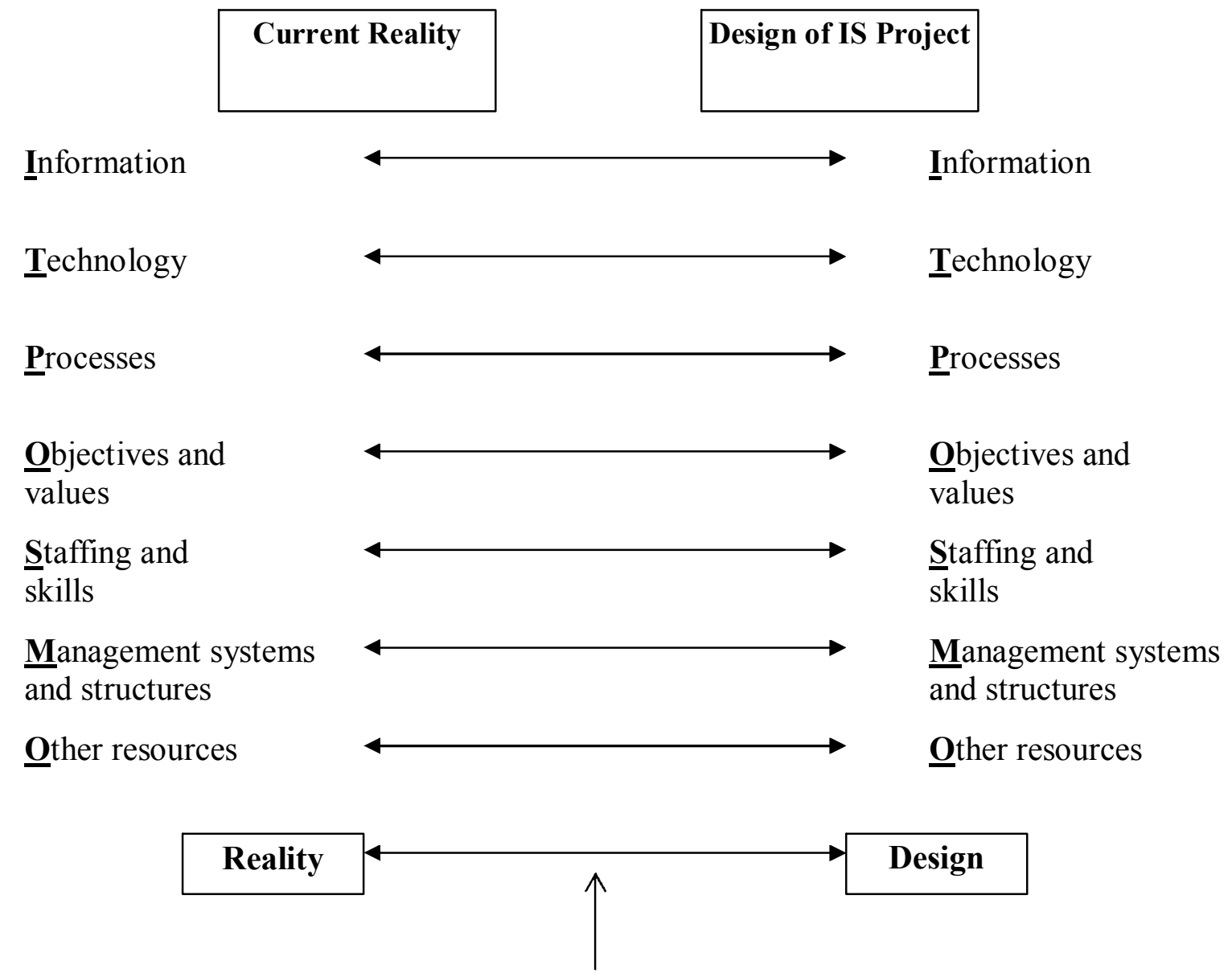

Gap

In specific terms, then, this paper will use this model to analyse why one particular ERP project in one particular developing country failed. The generalisability of the paper comes less from the specifics of this one project, and more from the development of a better conceptual base for understanding and managing ERP implementation in developing countries. The paper's main contribution is in applying the design - reality gap framework, and in demonstrating its analytical and practical value, including the derivation of recommendations for practice. 


\subsection{Research Methodology}

Our methodological requirements for this research were two-fold. We required a methodology appropriate for proof-of-concept; one that enabled a suggested conceptual framework to be tested in practice. And we required a methodology that would provide a depth and reliability of data sufficient to address all elements of the two models introduced to answer the main research questions.

Given these needs, we selected a single case study approach. Case study research is seen as relevant to exploratory work that tests a developed conceptual framework (Doolin 1996, Kanellis \& Papadopoulos 2008). It is also seen - particularly in the form of a single case study - as enabling "the researcher to investigate a phenomenon in depth, getting close to the phenomenon, enabling a rich description and revealing its deep structure" (Cavaye 1996:236; see also Darke et al. 1998). Recognising its value, the single case study approach has therefore been significantly used to investigate ERP system implementation and outcome (e.g. Al-Mashiri \& Zairi 2000, Guido et al. 2007, Sarker \& Lee 2003).

The case chosen is ERP implementation in a medium-sized Jordanian manufacturing company (anonymised as "Beta"). The primary data-gathering was undertaken in 2006, more than two years after an ERP implementation which had ultimately taken about nine months.

Validity in case study research requires triangulation (Yin 1994, Atkins \& Sampson 2002). Here, we utilise two different types of triangulation. First, triangulation of methods that combined analysis of organisational documentation, observation by sitting with different staff, and a set of semi-structured interviews.

The structured part of interview content was designed around three main components: outcome evaluation questions about the six elements of the DeLone and McLean model, estimation of design - reality gaps at the time of initial system introduction, and estimation of design - reality gaps at the time of interview. Then issues arising from that part of the interview were followed up with more in-depth unstructured questions, thereby providing a combination of qualitative and quantitative data. In total, each interview lasted for about one-and-a-half hours. Interviews were not taped since this was seen as potentially restricting openness of responses. Instead, notes were taken during the interview, and interviews were then written up more fully afterwards. Where any gaps or ambiguities were identified, these were clarified with the interviewee through subsequent contact by informal meeting or email. This also extended during the process of data analysis, which used the two conceptual models as the frame for analysis.

Documentary analysis involved access to company brochures and documents detailing system design, implementation and project management. It was used to provide general background information on the stakeholders and ERP system involved; but also to check specific data such as design specifications, organisational structures, and system responsibilities. Observation was undertaken of managerial and clerical staff responsible for ERP-related tasks. It was used to check data such as system modules, actual use and non-use of the whole and parts of the ERP system, issues with system data, technology in use, work processes, and level of skills. 
Periods of observation also involved informal conversations with staff used, for example, to corroborate other data about user satisfaction, and perceived gaps between design and reality.

The second form of triangulation used to improve validity was triangulation of sources, with the formal interviews conducted with three different groups: the external ERP consultants (two), senior internal managers associated with the ERP project (two), and internal company employees at both management and shopfloor levels who were ERP system users (four).

\section{ERP Case Overview and Outcome}

"Alpha Holdings" was established in Amman, Jordan in the mid-20 $20^{\text {th }}$ century and has become a regional conglomerate with more than two-dozen companies in ten countries. In the $1990 \mathrm{~s}$, it decided to move into production of a new type of industrial products and set up a new firm in Jordan: "Beta". Beta employs about 300 staff with a turnover in excess of US\$10m per year. It exports two-thirds of its output to other countries in the Middle East region and to European nations.

In 2000, Jordan signed a free trade agreement with the US and this impacted Beta in two ways: it looked for opportunities to export its goods to the US, and it was also concerned that US firms might be more likely to export competing goods to Jordan. Both of these were cited by IT staff and by the ERP project manager in Beta as key drivers for Beta to introduce an ERP system, aware as they were that many US firms were using such systems. They felt that, to compete in the US market and to compete with US exporters, an ERP system would be required. Within this decision, one can see echoes of rationality but there was a stronger strain of "mimetic isomorphism" the tendency of organisations to imitate the perceived actions of others they regard as peers (DiMaggio \& Powell 1991).

To progress its ERP project, Beta placed a request for tender in several Jordanian newspapers in 2003 seeking an implementation/consulting partner. Several consulting companies came forward and made presentations. A company named "Omega" was selected, along with its "eMAG" ERP system solution; eMAG being the product of a North American software firm for which Omega was a local partner. eMAG was to be implemented for about 40 users, integrating three types of module: financial (ledgers, assets), supply chain (purchasing, stock control, production control, sales), and human resource (HR, payroll).

The implementation team consisted of three client-side staff and five from Omega. The overall ERP project manager was Beta's IT manager, for whom this was a first experience with ERP. He was assisted by two IT staff who helped the consultants with basic IT support (e.g. fixing PCs) and with report building. Omega provided three area specialists who covered the financial (this specialist also doubling as the consultant-side project manager), supply chain, and human resource modules. They were assisted by an IT consultant, responsible for data conversion and report building, and a database administrator. A project steering committee of senior staff was set up and intended to oversee project progress and make strategic decisions. On a more regular basis, the consultant project manager reported to Beta's IT manager two or 
three times per week and discussed progress and decisions. The IT manager in turn reported to Beta's CEO.

The project was given a six-month timescale. This was planned to include basic configuration of the ERP system to client needs, based on an interview by the relevant consultants with key individual users. A rolling series of module dates was given, with each module having a one-week parallel run with the old information system, after which the module would go live and users were to stop using the old system. Two levels of training were provided - ordinary user training for those entering daily transactions, and super-user training for those who were intended to configure the system after the consulting firm's contract ended.

The stated reason for the selection of Omega and eMAG was cost; theirs was the lowest bid. When questioned, the ERP project manager listed a further set of internal driving forces that had led to the ERP initiative:

- Inefficiencies caused by the existing financial system used in the accounts department, and by the paper-based methods of other departments. These included the fragmentation of company data and the poor quality specifically of financial data.

- Difficulties caused by the rapid growth of the business in both size and product range, leading to a need to streamline the company's internal business processes.

However, another staff member in Beta pointed out that the identification of these internal driving forces came only after the decision to purchase the ERP system, during meetings with the consulting representatives from Omega. That initial decision, he maintained, was based on the intention of imitating US firms. We might see this as significant in the light of project outcomes because Nicolaou (2004) argues the initial driver behind ERP implementation significantly shapes the outcome. He differentiates "system-led" implementations where the main driver is simply wanting an ERP system, from "business-led" implementations where the main driver is the achievement of particular business improvements. He contends that system-led ERP projects have a higher risk of failure than business-led projects. This case certainly fits that assertion: no business case was presented to Alpha Holdings prior to the implementation decision and, as will be seen next, the outcome was largely failure.

\subsection{Case Outcome and Evaluation}

As noted above, the IS success model was used to shape part of the primary datagathering. Below, we use this to summarise the situation two years after implementation.

\section{ERP System Quality}

In terms of reliability and response time characteristics, most of the internal interviewees referred to problems with the ERP system. For example, one warehouse department employee stated "it is taking us more time now to complete the work; due to delay caused by frequent server overload. Even when the system is working the transactions are too slow". Likewise, one of the sales staff stated, "we had been told that by using the new system it will make it much easier for us to access information 
and perform our duties with less effort and time. However, this is not the situation, now it is taking us more time and effort than before". The ERP project manager accepted these problems, reporting that "there is a need to have more servers as we only have one, and the network bandwidth is not as required".

\section{ERP Information Quality}

In terms of data accuracy, the integrated nature of ERP systems means that inaccurate data entered into one ERP module can "infect" the operations of linked modules (Zhang et al. 2002). This was certainly the case in Beta because of poor quality data entry by company staff. The ERP project manager complained, "some employees do not understand the value of the data and the importance of being careful when entering data into the system. There is a lot of wasted time and effort in tracing and correcting each mistake".

Alongside the problems with data accuracy, there were also reported problems with the quality of the information being produced by the ERP system, particularly the content and format of management reports. For example, Beta's accounts manager stated, "the system failed to provide us with all the kinds of reports that we expected to be provided with". With the internal IT staff and external consultants unable to find a way round this, "we solved the problem by including the old Crystal Reports software in the ERP system menu to provide us with the needed reports as my employees have a good experience in using this software".

\section{ERP Use and User Satisfaction}

This combined dimension was seen to be made up from a number of sub-elements for evaluation (Nielsen 2002; Wong et al. 2004):

- User involvement and participation: beyond brief consultant interviews for a few, users reported that they had not been encouraged to participate in the implementation process. As one member of the IT staff indicated, "there was no role for the users in the implementation process; they were placed on the sidelines watching what is happening".

- Perceived usefulness of the system: responses from interviewees were mainly negative and often (see later) phrased implicitly in terms of design-reality gaps, such as the comment of one of the sales staff: "I think the problem is with the system itself; it is not designed for us. Many of the things that we used to do by using the old ways cannot be done by the new system". The only partial exception was the accounts department where the manager reported a more neutral overall perception: "my employees have no big problems with using the new system. The main problem is with the inaccurate data we receive from other departments".

- Levels of use: interview and observation indicated that only a small number of staff were actually using the system, mainly re-keying data from the still-running old systems into the ERP system for the purposes of reporting to the Alpha

Holdings head office. Overall levels of system use were therefore low. Alongside these specifics, interviewees were - in general terms - highly dissatisfied with the eMAG system. 


\section{Individual and Organisational Impacts of ERP}

Managerial staff within Beta were asked to rate the ERP system on a scale of one to ten in terms of positive impact on their individual work. The accounts manager was an outlier: he gave the system (though including the Crystal Reports "fix") a score of five, stating "even though the ERP system does not have any real impact on the other departments, I believe that in the case of my department it has a relatively good impact. Now, we can provide the management with the financial information they want. I really think that this had a positive impact on the senior management decisions, at least now they can know how much we earned or lost in each month".

Other managers disagreed, and their attitude was exemplified by the sales manager who gave the ERP system a score of one, stating "I do not think that the ERP system had any positive impact on the daily work or decisions in most of the departments. The work is conducted as before introducing the ERP system except that now we have to enter all the data we got into the system by the end of each day in order to sort out the financial information, which put on us more pressure and effort".

Regarding organisational impacts, the company had not conducted any evaluation of ERP impact in terms of financial payoff or achieved objectives; the two measures mainly associated with organisational impact evaluation. However, when asked, managers felt the system had neither increased sales nor reduced costs, so there seems little likelihood that it had generated a positive return on an investment estimated to be around US $\$ 150,000$ in direct terms. The problems of inter-departmental inefficiencies and fragmented business processes remained. Financial information was being produced by the system but, if this was an imitation of the claimed benefits achieved through ERP by US companies, it was but a very pale imitation.

\section{Overall Evaluation}

Heeks (2002:101-102) divides information systems projects into one of three evaluated outcomes:

- Total failure: "an initiative never implemented or in which a new system was implemented but immediately abandoned".

- Partial failure: "major goals are unattained or in which there are significant undesirable outcomes".

- Success: "most stakeholder groups attain their major goals and do not experience significant undesirable outcomes".

Beta's ERP system was implemented and it has not been abandoned. However, it is certainly not a success. Based on the evaluation evidence gathered, we can say that it is a partial failure, verging towards the "total failure" end of the spectrum. Faced with all of the problems, the company's management decided to return to the old ways of doing things and the old information systems for the firm's daily activities. The option of discarding the system was considered but, according to one of the IT staff, this could not be accepted because of the quite public investment of quite large sums of money in the ERP project.

Instead, then, as described above, this became just a "hollow ERP" implementation. Core data handling was undertaken by the old information systems, with finance- 
related data re-keyed into the ERP system at the end of each working day with the help of the company's IT staff. This enabled the company to give the outward appearance of an ERP implementation for the purpose of monthly financial reporting to Alpha Holdings. For image purposes, if asked, it could also say that it is an ERP user.

\section{Explaining ERP Failure}

\subsection{Analysing the ERP System's Initial Design—Reality Gap}

In this section, we will use the design - reality gap model presented earlier to analyse the gap between the initial design of the ERP system, and the reality of Beta just prior to ERP implementation in 2003, using qualitative analysis followed by a quantitative rating that is a composite from interviewee questioning, documentary evidence and our own analysis. On the rating scale, 0 would represent no gap or difference between information system design and organisational reality; 5 would represent some degree of difference; 10 would indicate complete and radical difference between design and reality. This analysis will be structured according to the ITPOSMO dimensions.

\section{Information: Gap Rating 8}

The consulting company, Omega, proposed no changes to the one-size-fits-all data architecture of the eMAG ERP system. This created a significant mismatch with reality. For example, the design assumed the existence of data that was not readily available, such as a list of accurate quantities of all items or materials existing in the company's warehouse; a list of all the company's suppliers; and core data related to the creation of a needed bill of materials of produced products.

Some of the data required by the ERP system design did not exist at all in the company. For example, the design assumed the existence of a "stock bin" for each item stored in the company's warehouse; this stock bin reflecting the location of an item on the warehouse shelves. In reality, such data did not exist because this was not the followed procedure for storing items in the warehouse.

\section{Technology: Gap Rating 8.5}

eMAG's design assumed the existence of a strong local area network, servers, personal computers, and broadband Internet connections. In reality, Beta had no LAN, no servers and just a very slow dial-up Internet link. The only available computers were a small number of old PCs in the accounts department.

\section{Processes: Gap Rating 8}

ERP system design assumes a set of organisational processes that match best practice (Davison 2002). In reality, Beta's work processes differed greatly from this ideal. In general, internal processes involved duplications, delays and reworking that made them quite inefficient. More specifically, processes reflected Jordanian norms. For example, customers were allowed to pay by instalments or to write post-dated 
cheques for future deposit. Neither of these was part of eMAG's module design; an example of what Soh et al (2000) call an operational or functional misfit.

\section{Objectives and Values: Gap Rating 9}

eMAG's design, like that of other ERP systems, assumed that the inscribed business "best practices" including cross-organisational data flows, were valued by key project stakeholders and that they shared the system objectives of "cost reduction", "increased revenue", "better management decision making" and "faster, more accurate transactions" (Davenport et al 2002:25).

In reality, few project stakeholders shared these objectives and values:

- Beta's CEO and one or two of the most senior managers shared some of them but only to the extent of sanctioning, rather than actively championing, the ERP project.

- Most senior and other managers did not share them. They were happy with the old system because it represented to them a source of power and influence, and any attempt at greater sharing of information was considered a threat. They saw only limited need for the stated objectives, and were resistant to the project.

- Almost all Beta employees did not share them. They instead saw eMAG as a threat to workload or jobs.

- Omega's consultants did not share them; their objective was to finish the job as quickly as possible, get paid, and move on to the next contract.

\section{Staffing and Skills: Gap Rating 8.5}

ERP system design assumes the existence of "a balanced multifunctional team" drawing skills and knowledge from a variety of areas, including competencies for both implementation and use of the system (Sarker \& Lee 2003:819). It also assumes the full-time assignment of client staff members who engage with the implementation process to explain current organisational processes and to help introduce best practice.

But, in reality, such competencies were not present. Project team members - both from the client side and the Omega consultants - were new to ERP implementation, and they lacked many of the necessary skills. Beta staff members devolved implementation to the consultants, with little internal engagement. And, while one or two Beta staff had IT skills, the great majority had either very basic skills or none.

\section{Management Systems and Structures: Gap Rating 8}

ERP design requires the existence of "a modern management structure" that allows "decentralised decision making" by giving operational-level employees both access to information, and empowering them to make decisions (Rajapakse \& Seddon 2005b:5). This was not the reality in Beta: it had a centralised management structure with centralised data access and centralised decision-making.

More specifically, the eMAG system design assumed the introduction of new IT managerial positions to oversee the ERP system, the absence of some other managerial positions, and changes in supervisory responsibilities, as compared with 
the firm's existing reality. It also incorporated within its design the presence of a separate procurement department and a separate sales department. In reality, neither of these existed in Beta.

The lack of Beta staff engagement was noted above but, further, ERP project design requires the existence of central and senior leadership within the client organisation; able, for example, to resolve conflicts, mobilise resources, and avoid duplications (Sumner 2000). In reality, no such central leadership initially existed.

\section{Other Resources: Gap Rating 5}

ERP system design requires two types of implementation expenditure: "one-time costs" to introduce the system and then "ongoing annual costs" (Hamilton 2002:45). In reality, Beta had set aside funds for both types of costs. ERP project design requires a timescale that can range from twelve months to four years (Mabert et al 2001). In reality, the project was given only six months for full implementation.

\section{Analytical Summary}

Taking a basic, unweighted approach to each of the seven dimensions, we can aggregate the gaps to get an overall design - reality gap score of 55 prior to system implementation. Comparing this to Table 1 (adapted from Heeks 2006), we can see that the prediction for this project - that it "may well fail", verging close to "will almost certainly fail" - matches well with the actual outcome.

Table 1: Predicted Project Outcomes From Overall Design-Reality Gap Scores

\begin{tabular}{|l|l|}
\hline $\begin{array}{l}\text { Overall Design- } \\
\text { Reality Gap Score }\end{array}$ & Likely Project Outcome \\
\hline $57-70$ & $\begin{array}{l}\text { Project will almost certainly fail unless action is taken to } \\
\text { close design-reality gaps }\end{array}$ \\
\hline $43-56$ & $\begin{array}{l}\text { Project may well fail unless action is taken to close } \\
\text { design-reality gaps }\end{array}$ \\
\hline $29-42$ & $\begin{array}{l}\text { Project might fail totally, or might well be a partial failure } \\
\text { unless action is taken to close design-reality gaps }\end{array}$ \\
\hline $15-28$ & $\begin{array}{l}\text { Project might be a partial failure unless action is taken to } \\
\text { close design-reality gaps }\end{array}$ \\
\hline $0-14$ & Project may well succeed \\
\hline
\end{tabular}

Table 2 summarises the individual dimensional gap scores and compares them to the ratings provided by Heeks (2003). Although it suggests four dimensions technology, processes, objectives and values, and staffing and skills - as the most likely causes of ERP project failure, the scores on all but the "other resources" dimension are so close as to indicate a broad base of risk factors for the project. 
Table 2: Design—Reality Gap Dimensions As Likely Causes Of Failure; PreImplementation

\begin{tabular}{|l|c|c|}
\hline Dimension & Gap Score & $\begin{array}{c}\text { Likelihood as Cause of } \\
\text { Failure }\end{array}$ \\
\hline Information & 8 & Likely \\
\hline Technology & 8.5 & Very Likely \\
\hline Processes & 8 & Very Likely \\
\hline Objectives \& Values & 9 & Very Likely \\
\hline Staffing \& Skills & 8.5 & Very Likely \\
\hline Management Systems \& Structures & 8 & Likely \\
\hline Other Resources & 5 & Possible \\
\hline
\end{tabular}

\subsection{Analysing Design-Reality Gaps During ERP Implementation}

Neither information systems design nor organisational reality are static. They change constantly and hence so too do design-reality gaps. Successful project implementation is possible even when initial gaps are large, if measures can be taken to change system design and/or change organisational realities in order to ensure gap closure (Heeks 2006). Our next analytical step, then, is to analyse what happened to the initial gaps during ERP implementation.

\section{Information: Gap Rating 6.5}

The Omega consultants convinced Beta client staff to make some changes in the format of their data so that it would fit with the design requirements of the eMAG ERP system. For example, company product identifiers were changed from those that included a textual indication of the nature of the product to a solely-numeric code. Much of the company's data was stored as hard copy. This reality was changed with much (though not all) of it being digitised. Where feasible, this was entered onto the ERP database, though a number of transcription errors occurred during this process.

However, as noted above, much of the data required by the ERP system design from a number of the parts of the company was not available. As a result, fields in several database tables had to be left blank, and proper integration between tables was not feasible as per ERP norms. In part this arose because the consulting team fell between two stools. They began customising the ERP system so that its design came closer to the reality of client processes (see below). As a result, though, problems began to emerge in the integration between modules. They were unwilling or unable to take customisation further to try to fix either these problems or the informational problems with the database tables.

There were also reports that Beta managers wanted in order to fit with their customary decision-making. The Omega consultants were unable to produce a significant number of these from the eMAG system and, hence, the old IS were returned to (indeed, Davison (2002) comments more generally that ERP's real-time design approach mismatches the traditional "management report" style of working). 
Overall, then, there was some, but limited, progress in closing the informational design—reality gap.

\section{Technology: Gap Rating 6}

New information technology was introduced into Beta during ERP implementation, thus changing the reality of its IT infrastructure. However, in order to create a lowcost (and hence winning) bid for the work, Omega had proposed the installation of a low-cost IT infrastructure. As a result, elements of that infrastructure were below the expected design norm for eMAG:

- LAN speed: $40 \mathrm{Mbps}$ in reality, compared to a design norm of $100 \mathrm{Mbps}$.

- Server power: one Dell PowerEdge 6600 server in reality, compared to a design norm of two.

- Internet connection: $256 \mathrm{kbps}$ in reality, compared to a design norm of $1 \mathrm{Mbps}$.

- PC specification: Pentium II or III - even some Pentium I PCs - in reality, compared to a design norm of Pentium 4-based specifications.

This hampered the functioning of the system, and led some gap between design and reality to remain.

\section{Processes: Gap Rating 6}

Standard practice in many ERP implementations has been to force a match between client business processes and ERP system design through business process reengineering (BPR). This was attempted by the Omega consultants. For example, as a baseline activity they undertook an analytical mapping of current company business requirements and processes onto ERP software functionalities.

Unfortunately, the consultants lacked experience in BPR, and they also invested insufficient time and effort. As a result, many of suggested process redesigns were infeasible or inappropriate. For example, the consultants proposed that Beta should adopt the payment approaches designed into the ERP system. Beta managers probably quite rightly - rejected this as inimical to Jordanian ways of working, and likely to lose them customers.

Equally, some system redesigns were not undertaken so that, for instance, Beta's requirement for handling a high volume of product master files could not be met by eMAG. Where the consultants did try to redesign the ERP system to compensate for the inability to change company business processes, they were drawn into heavy customisation of the software that went well beyond basic configuration, including changes to software code. This created its own problems including those of integration already noted.

Most serious of all was the "customisation" of the ERP system's human resources module, which ended up with use of a quite separate HR software package, called Tantash. Alongside causing serious time and financial overruns, this also fundamentally undermined the main purpose of ERP - integration - because the Tantash package was autonomous from the eMAG system. It did, though, enable some measure of design - reality gap closure, at least in this particular part of the company's operations. 


\section{Objectives and Values: Gap Rating 9}

No actions were taken during implementation in order to address the resistance to ERP espoused by most Beta employees and managers. There was no user participation beyond the odd interview and users had no input to the project, let alone control. No change management strategy was discussed let alone implemented. Where managerial input was required, it was passed down to some junior staff member like a hot potato. Top management remained detached and disinterested. And there were open arguments between some managers and the consultants. As a result, no design - reality gap closure can be seen. Indeed, if anything, the mismatch between system design and actual objectives increased rather than decreasing.

\section{Staffing and Skills: Gap Rating 7.5}

An ERP implementation and use training programme was provided by the Omega consultants, lasting two weeks. However, it fell well short of good practice. The consultants lacked not only training experience but also sound knowledge of ERP usage and, as noted above, sound knowledge of the realities of Beta's ways of working.

Only very brief training materials were provided, and there was no user documentation or support. As a result, employees stated that they came away without a clear idea about the nature, purpose and use of an ERP system. As per the previous dimension, the training therefore failed to change staff attitudes. But it also failed to impart necessary skills. When staff came to use the system after training, they found many functions of which they were completely ignorant, with no way to obtain answers to the immediate operational problems that faced them, something compounded by the various limitations of the ERP system discussed earlier.

The super users who were trained to configure the system were selected without consideration of their IT skills, education or experience. Combined with the poor quality of the training, this left them unable to work on the system.

As a result, while there was some diffusion of skills, it was shallow and, for some elements, short-lived when skills picked up on training atrophied through disuse. Gap closure was therefore rather limited.

\section{Management Systems and Structures: Gap Rating 6.5}

There were structural changes introducing into Beta during project implementation. New departmental structures were introduced, matching the ERP system design. However, managerial responsibilities of company supervisors and managers were not changed, and the system of centralised control and decision-making remained.

The central and senior leadership structure - the project steering committee - was created for the project; as per the requirements for ERP system implementation. It consisted of the company CEO, senior executives and the Omega consultants. Its remit was to make all main implementation decisions, and to solve problems. 
Unfortunately, this intended change to organisational reality fell short in practice. Most of the senior executive members did not attend steering committee meetings either not having, or more often not making, time. As a result, decisions were left unmade, and problems were left unsolved because more junior project team members were not authorised to make decisions. Where senior managers did become involved - and partly because of the integrative and data-sharing nature of ERP applications they were often drawn into conflict with each other.

As a result, this intended new structural reality did not function as needed and there was only limited progress in closing the management systems and structures gap.

\section{Other Resources: Gap Rating 5}

In order to win the contract, the Omega consultants had put in a low-cost, shorttimescale bid. In terms of time, the explicit design requirement proved much too short and implementation slipped from six months to nine. Even this required a huge workload from those involved, yet it was still not enough to match the (implicit) design requirement for implementation of a good quality ERP system. As a result, corners were constantly cut during implementation, with so many activities done quickly rather than being done well. One cannot say that there was any gap closure here.

In terms of money, both design requirement and reality changed leaving little gap between the two: more money was needed to complete the design, but that money was then found. Beta interviewees were hesitant to talk about costs, but indicated that the final direct cost of the ERP implementation was around US\$150,000. They indicated that this over-ran the original bid but for reasons of commercial confidentiality, were unwilling to say by how much.

Ongoing costs of the ERP system were also much higher than expected though, again, were funded. The intention was that the consulting firm would be dispensed with after implementation, leaving the super-users to undertake any necessary subsequent system configuration. The inability of the super-users to do this has already been noted. We also noted the consultants had gone beyond system configuration to customisation of software code and database. As a result, Beta became dependent on the consultants and was forced to sign a long-term support contract with Omega. 
We can see from Table 3 that the gaps between design and reality did close on a number of dimensions. However, that closure was limited.

Table 3: Design—Reality Gap Dimensions As Likely Causes Of Failure; PostImplementation

\begin{tabular}{|l|c|c|c|}
\hline Dimension & $\begin{array}{c}\text { Gap } \\
\text { Change }\end{array}$ & Gap Score & $\begin{array}{c}\text { Likelihood as Cause of } \\
\text { Failure }\end{array}$ \\
\hline Information & -1.5 & 6.5 & Likely \\
\hline Technology & -2.5 & 6 & Possible \\
\hline Processes & -2 & 6 & Possible \\
\hline Objectives \& Values & 0 & 9 & Very Likely \\
\hline Staffing \& Skills & -1 & 7.5 & Likely \\
\hline Management Systems \& Structures & -1.5 & 6.5 & Likely \\
\hline Other Resources & 0 & 5 & Possible \\
\hline
\end{tabular}

Again, taking a basic and unweighted approach, we get an aggregate design — reality gap score of 46.5 points following system implementation. The project still falls - see Table 1 - into the "may well fail" prediction; a prediction that was borne out. That would only change if much greater alterations were made to either the system's design, or to Beta organisational realities.

Perhaps most notable is the inability to close the design - reality gap on the "objectives and values" dimension. It is this above all that tells us if stakeholders are motivated to make a project succeed. That they were not, even after the ERP system had been installed, fundamentally undermined this project.

\section{Discussion}

The ERP system investigated in this paper can be classified as a failure. The explanation for this has been offered not in terms of specific factors but through a more overarching understanding: the design - reality gap model. Our analysis has shown that, from the perspective of the model, this ERP project began badly. A set of assumptions and requirements were designed into the ERP system and its broader project. These significantly mismatched the realities to be found in the client organisation - required information was not present, the technology infrastructure was much more basic, work processes were very far from best practice, and so forth.

Of itself, this does not mean a failure will ensue. Many ERP system designs mismatch organisational reality at the start of implementation. This is inherent to the nature of organisational change: that the "bad" problems of current reality will differ from "good" solution offered by the new project.

The key issue, then, is what happens during implementation. Can the project team work to change organisational reality through the introduction of the new system 
(and/or modify the system design to reduce the more extreme mismatches to reality)? There was certainly an attempt to do this in the case of Beta but the impact was far too limited, leaving the base of skills, data, technology, etc within the organisation too far-removed from what a successful ERP system would require.

Their failure to close design - reality gaps helps us understand why this ERP system failed: the model thus acts as a post hoc analysis tool focusing largely on identification of risk. But the design - reality gap model could also be used for risk mitigation; suggesting ways to move forwards from the current situation by closing particular dimensional gaps and so increasing the likelihood of project success.

One route would be redesign of the ERP system to make it more nearly adhere to current information, processes, systems, etc found in the client organisation, Beta. The danger here is, the more nearly the system design approximates to company reality, the less it changes that reality and the more it becomes a set of separate systems that are not integrated and not ERP. We have also seen the potential problems of high levels of customisation of an ERP system's design: not just the fact that it was done badly in this case but the loss of main vendor support, the need for complete rework after any upgrade, and ongoing consultant dependency that it entails.

An alternative route is to change current reality to make it more nearly adhere to the assumptions and requirements of ERP system design. Examples could include:

- Information: broadening the base of data gathered within the organisation, to reduce the number of blank fields in the ERP database.

- Technology: greater investment in IT infrastructure to make the technology reality more closely match the infrastructural requirements inscribed into ERP design.

- Process: more skilful planning of improvements to Beta's work processes to bring them at least somewhat closer to ERP norms.

- Objectives and values: adoption of a simultaneous programme of organisational change, aiming to engage internal stakeholders in the ERP project, and to nudge organisational culture more towards ERP-like values.

- Staffing and skills: a properly-undertaken training programme that would teach purpose as well as skills; would teach skills directly related to what each trainee faces in the workplace; and would offer a well-resourced post-training support system. In this way, matching real skills more closely to required skills.

- Management systems and structures: project leadership from the top that would drive synergy between actual systems/structures and those assumed within system design.

- Other resources: more time and more money allowed for the project.

Design - reality gap closure recommendations like these along each dimension do provide an agenda for risk mitigation. However, we must offer two caveats.

First, the design — reality gap model is blind to the qualities of design and of reality: it tells us nothing about whether stakeholders would see them as "good" or "bad"; only that the mismatches between design and reality increase the risk of failure.

We may therefore wish to interrogate ERP system design; asking whether this is the most effective approach for a Jordanian organisation. Are the problems experienced 
simply a question of the Jordanian organisation differing significantly from the Western best practice inscribed into ERP design? Or is there an additional - or even alternate - issue that Western best practice does not represent the most effective means for a Jordanian business to conduct itself? If, by stress and struggle, Beta matched its reality to the demands of ERP system design, would this place it in the most effective business position or not? Put another way, does some of the resistance to ERP derive not from personal interest, but from a legitimate and valid concern that this is leading the company in the wrong direction; of which the issue of customer payments might be one example? (We will leave aside whether the same question can be asked in industrialised countries: are ERP projects barking up the wrong tree and making firms less, not more, competitive; see, e.g., Ciborra 2002.) Information systems literature takes a general view that resistance is a "bad thing". But perhaps it isn't always. Perhaps sometimes resistance is, at least in part, a signal that the proposed system is taking the organisation in the wrong direction.

Second, how feasible are the kind of gap closure suggestions made above in a developing country context? We could, for instance, have prescribed selection of a more experienced consultancy as a prophylactic to avoid some of this case's identified failings. But many developing country businesses find themselves facing a choice between a set of equally-inexpert vendors (according to one consultant interviewee, this is very much the case in Jordan; see also Rajapakse \& Seddon 2005a). In such situations, perhaps the lowball bid is the logical one for a client to accept; the one that risks losing the least amount of money. And perhaps there are serious barriers to both redesign and altering current realities because of a foundational lack of expertise.

Finally, what about culture? As noted in our earlier review of literature, one of the most-common findings in factoral studies is that cultural problems are related to ERP failures. Other studies, too, identify a central role for culture in ERP implementation (e.g. Stewart et al 2000; Skok \& Döringer 2001; Molla \& Loukis 2005). We have also seen this to be the case for Beta. Culture - represented here as part of the "objectives and values" dimension of the design - reality gap model - was estimated to show not only the largest difference between design and reality but a difference that persisted throughout implementation, and which therefore was arguably the single most important reason for ERP failure.

To explore this issue further, we reach, with some hesitation (see below), for Hofstede's (2003) views on culture. Hofstede's work represents the most widely-cited on culture, and is a set of ideas that has been seen before as relevant to the study of ERP systems (e.g. Bendoly et al. 2006, El-Sawah et al. 2008). It also fits well with our desire to understand the impact of the broader national culture in Jordan, which we did through the following dimensions:

- Uncertainty avoidance: like many in other developing countries, Jordanians are rated as having a high level of uncertainty avoidance (Deresky 1997). Unlike "Western cultures", they "feel threatened by ambiguous situations, and have created beliefs and institutions that try to avoid these" (Mead 1998:37). They give a high value to job security (ibid). Any change project brings uncertainty with it, and will thus be threatening to those with high uncertainty avoidance. As Beta's IT manager noted, "the project faced a lot of resistance from the employees; they did not want any new changes to their jobs. The employees had a lot of uncertainty and anxiety toward the project; they resisted the project as a way to 
protect their jobs". ERP projects perhaps particularly do this in developing countries because of the significant change in current working practices that they demand.

- Individualism: Jordan (again like many developing countries) rates low on individualism and highly on collectivism; "the tendency of people to belong to groups or collectives and look after each other in exchange for loyalty" (Deresky 1997:74). But collectivism can create a sense of loyalty to family and social groupings that, alongside low salaries, makes for a low level of commitment at work (Hill et al 1998; Rajapakse \& Seddon 2005b). This was something noted by the ERP project manager: "we have staff with low levels of commitment, they act like they are forced to come to work every day". This was partly seen to explain the lack of engagement with the ERP project or its values, and the poor quality of work - such as digitisation - undertaken with the ERP system.

- Power distance: Jordanians are seen to accept an inequality of power distribution and, hence, to accept centralised decision-making as the norm, and that information will be used as a component of power rather than - as per ERP norms - shared as an organisation-wide resource (Deresky 1997; Hill et al 1998). The ERP project manager therefore noted that "managers were not happy with the idea of sharing information among the subordinates. They asked for restricted access to information for themselves". Likewise, as already noted, ERP-designed assumptions of devolved decision-making run directly counter to a culture of centralisation.

In many ways, these views on culture are dangerous sentiments (e.g. Walsham 2002; Shoib \& Nandhakumar 2003). They can create caricatures that homogenise culture at a national level; yet culture has organisational, group and individual components. They present a static view of culture; yet culture is dynamic. They offer a single cultural profile; yet individuals will often be subject to multiple, potentially conflicting, cultural currents.

However, we should not reject these ideas entirely. The widespread use of Hofstede's ideas suggest they reflect a perceived reality, and a perceived utility in understanding and engaging with organisational practice. What they suggest is potentially deep institutional forces in Jordan - and perhaps in some other developing country contexts - that run counter to the values inscribed into ERP systems design.

This provides us with a valuable complement to the case research reported above, by suggesting reasons why it may be hard to close the gap on the "objectives and values" dimension. Given the centrality of this dimension to motivation and drive for any IS project, the difficulty of such gap closure may in turn make it hard to find the motive force for closing gaps on other ITPOSMO dimensions. The list of gap closure ideas presented earlier may therefore be logical in theory, but harder to achieve in practice.

\section{Conclusions and Implications}

Developing country expenditure on ERP is growing, and these systems can undoubtedly deliver benefits to organisations in developing countries (Molla \& Bhalla 2006; Kamhawi 2008). However, high failure rates continue to block the delivery of 
such benefits. Research to date, though, often appears partial, focusing on only some aspects of system outcome and/or focusing only on certain specific implementation factors.

This research therefore sought to identify conceptual models that would provide a more holistic perspective, and that would answer two questions.

First, how can the outcome of an ERP project be classified as a success or failure? Here, we made use of DeLone \& McLean's model; one that is fairly well-known in IS research generally but which does not appear to have been used very much to date in ERP research. We demonstrated that it provides an appropriate framework for data gathering, analysis and presentation in relation to the outcome of an ERP project; and a framework that can be integrated easily with Heeks' three-way outcome categorisation of total failure, partial failure, and success in order to provide a final classification.

Our second question asked how we can understand why a particular ERP project outcome occurred. For this, we described development of the design - reality gap model and showed how it can be used to analyse why one particular ERP system largely failed. Its explanation is that ERP systems fail due to too large a gap between ERP design and client organisation reality; a gap that remains unclosed during implementation, and which exists on several dimensions.

Some of those specific dimensions echo individual factors that earlier studies have identified. However, the design - reality model represents a progression beyond those studies because it is more systematic and comprehensive; drawing together all the separate factors of which earlier work has typically only focused on one or two items. It is more dynamic; helping to track the changing risks and likelihood of success or failure over a project's lifespan. It is more analytical, explaining the root cause of difficulties in a consistent manner for all factors, and through reference to a strong theoretical foundation that draws on ideas such as inscription from the literature on sociology of technology. And it is also more contingent, avoiding the implicit "onesize-fits-all" ideology that underpins some earlier ERP analyses and, instead, allowing a sensitivity not just to different national settings but to different organisational settings; a sensitivity that is particularly apposite for work on developing countries.

We therefore particularly hope that this new model will be used by other researchers and by practitioners as a means to understand, and act on, the processes of ERP implementation. Our own interest and application of the model has been in a developing country context. However, there is no a priori reason why the model would not also be applicable to ERP or other information systems applications in industrialised countries.

\subsection{Implications}

The new design - reality gap model presented here is a conceptual and analytical tool, but one that can be readily used by ERP project practitioners. As used here in the main body of the paper, it is demonstrably a tool that project managers or consultants could use for post hoc risk identification: most typically as in this case as a means for understanding why an ERP application wholly or partially failed. Given the 
recommendations made in the discussion section we can equally see it being applied as a "per hoc" tool; one that will identify risks during the process of implementation. And Section 4.1 demonstrates its potential as a pre hoc tool, usable at the time of initial feasibility study. For both pre hoc and per hoc application it can not only identify risks but also - using the scoring approaches outlined in Tables 1 and 2 offer some prediction of likely project outcome.

Risk identification has an important value in ERP project management. However, risk mitigation is arguably more important. The design - reality gap model helps identify risk mitigation actions for challenged ERP projects through its general prescription that risks can be reduced by changing organisational reality to more closely match ERP design, or by changing ERP design to more closely match organisational reality.

Project managers can do this for specific ITPOSMO dimensions, as exemplified for the Beta project in the Discussion Section above. But there are also more generic actions that can be identified on the basis of their gap-closing potential. Examples would include:

- Mapping organisational realities: finding ways to expose the true situation within the organisation, and integrate that into implementation processes. One example would be the use of soft systems techniques, such as "rich pictures", which have a good track record of mapping realities (Checkland \& Holwell 1998).

- Using hybrids: hybrid ERP professionals are those who combine an understanding of information systems with an understanding of the main business of the client organisation. Such individuals could therefore act as a bridge between the ERP system design and organisational reality, helping to recognise and reduce gaps.

- Being incremental: to the extent possible with an ERP system, breaking the overall change down into smaller steps and therefore reducing the extent of gap between design and reality that is undergone at any one time.

Having said this, the caveats outlined above must be recognised. Despite the practical value of the design - reality model for risk identification and mitigation, ERP implementations in many developing country organisations are likely to remain highly challenging.

Finally, what are the implications for future research? Two elements of the contingency literature were identified earlier but not followed in developing this paper's model. Future research could follow these up, analysing ERP implementation in terms of the fit between dimensions i.e. investigating whether mismatches between factors such as organisational processes, staffing, structures and technology are the cause of problems. Or analysing any mismatch between the assumptions and expectations of different stakeholder groups. The design - reality gap model could be interpreted as a simple form of this, encompassing and comparing the views of ERP designers and of ERP users. However, stakeholder groups in practice are more numerous than this, and so further research would be needed to investigate this properly.

We hope, too, that the design - reality gap model will form the basis for future research. Such work could seek to broaden the current study; applying the model to ERP cases in other settings, or using the model longitudinally during the implementation process. Or, the work could seek to deepen, for example, utilising the 
ideas of inscription to understand how assumptions come to be built into both ERP system and project designs, and how - if at all - they can be modified.

\section{References}

Akrich, M. (1992), "The de-scription of technical objects", in W.E. Bijker and J. Law (Eds), Shaping Technology/Building Society, MIT Press, Cambridge, MA, pp. 205224.

Aladwani, A. (2001), "Change management strategies for successful ERP implementation", Business Process Management Journal, Vol. 7 No. 3, pp. 266-275.

Al-Mashiri, M. \& Zairi, M. (2000), "Information and business process equality: the case of SAP R/S implementation", Electronic Journal of Information Systems in Developing Countries, Vol. 2 No. 4, pp. 1-15.

Atkins, C. \& Sampson, J. (2002), "Critical appraisal guidelines for single case study research", paper presented at the 10th European Conference of Information Systems, 6-8 June, Gdańsk, Poland.

Barki, H. \& Pinsonneault, A. (2002), Explaining ERP Implementation Effort and Benefits With Organizational Integration, Cahier du GReSI, Montreal, Quebec.

Beeharry, A. \& Schneider, G.M. (1996), "Creating a campus network culture in a newly developing economy", Information Technology for Development, Vol. 7 No. 1, pp. 3-16.

Bendoly, E., Bachrach, D.G., Wang, H. \& Zhang, S. (2006), "ERP in the minds of supervisors: joint roles of task interdependence and cultural norms", International Journal of Operations \& Production Management, Vol. 26 No. 5, pp. 558-578.

Bocij, P., Chaffey, D., Greasley, A. \& Hickie, S. (2003), Business Information Systems, $2^{\text {nd }}$ edn, Pearson Education, Harlow, UK.

Boon, J.A. (1992), "Information and development", The Information Society, Vol. 8 No. 4, pp. 227-241.

Cavaye, A.L.M. (1996), "Case study research: a multi-faceted research approach for IS", Information Systems Journal, Vol. 6 No. 3, pp. 227-242.

Checkland, P.B. \& Holwell, S. (1998), Information, Systems and Information Systems, Wiley, Chichester, UK.

Ciborra, C. (2002), The Labyrinths of Information: Challenging the Wisdom of Systems, Oxford University Press, Oxford.

Darke, P., Shanks, G. \& Broadbent, M. (1998), "Successfully completing case study research: combining rigour, relevance and pragmatism", Information Systems Journal, Vol. 8 No. 4, pp. 273-289. 
Davenport, T., Harris, J. \& Cantrell, S. (2002), The Return of Enterprise Solutions: The Director's Cut, Accenture available at: http://tinyurl.com/6pzmcg (accessed 28 Jun 2009).

Davison, R. (2002), "Cultural complications of ERP", Communications of the ACM, Vol. 45 No. 7, pp. 109-111.

DeLone, W. \& McLean, E. (1992), "Information systems success: the quest for the dependent variable", Information Systems Research, Vol. 3 No. 1, pp. 60-95.

Deresky, H. (1997), International Management: Managing Across Borders and Cultures, $2^{\text {nd }}$ edn, Addison-Wesley, New York, NY.

DiMaggio, P.J. \& Powell, W.W. (1991), "The iron cage revisited: institutional isomorphism and collective rationality in organizational fields", in W.W. Powell \& P.J. DiMaggio (Eds), The New Institutionalism in Organizational Analysis, University of Chicago Press, Chicago, IL, pp. 63-82.

Doolin, B. (1996), "Alternative views of case research in information systems", Australasian Journal of Information Systems, Vol. 3 No. 2, pp. 21-29.

El-Sawah, S., El Fattah Tharwat, A.A. \& Rasmy, M.H. (2008), "A quantitative model to predict the Egyptian ERP implementation success index", Business Process Management Journal, Vol. 14 No. 3, pp. 288-306.

Federici, T. (2009), "Factors influencing ERP outcomes in SMEs: a post-introduction assessment", Journal of Enterprise Information Management, Vol. 22 Nos. 1/2, pp. 81-98.

García-Sánchez, N. \& Pérez-Bernal, L.E. (2007), "Determination of critical success factors in implementing an ERP system: A field study in Mexican enterprises", Information Technology for Development, Vol. 13 No. 3, pp. 293-309.

Guido, C., Lelio, R \& Pierluigi, R. (2007), "A methodological approach to assess the feasibility of ERP implementation strategies", Journal of Global Information Technology Management, Vol. 10 No. 4, pp. 35-53.

Hamilton, S. (2002), Maximizing Your ERP System, McGraw-Hill, New York, NY.

Heeks, R.B. (2002), "Information systems and developing countries: failure, success and local improvisations", The Information Society, Vol. 18 No. 2, pp. 101-112.

Heeks, R.B. (2003), Design—Reality Gap Analysis, eGov4Dev, IDPM, University of Manchester, UK, available at:

http://www.egov4dev.org/success/techniques/idfailure drg.shtml (accessed 28 Jun 2009).

Heeks, R.B. (2006), Implementing and Managing eGovernment, Sage Publications, London. 
Hill, C., Loch, K., Straub, D.W. \& El-Sheshai, K. (1998), "A qualitative assessment of Arab culture and information technology transfer", Journal of Global Information Management, Vol. 6 No. 3, pp. 29-38.

Hofstede, G, (2003), Culture's Consequences, $2^{\text {nd }}$ edn, Sage Publications, London.

Hong, K.K. \& Kim, Y. G. (2002), "The critical success factors for ERP implementation: an organizational fit perspective", Information \& Management, Vol. 40 No. 1, pp. 25-40.

Horton, F.W. \& Lewis, D. (eds.) (1991), Great Information Disasters, ASLIB, London.

Huang, Z. \& Palvia, P. (2001), "ERP implementation issues in advanced and developing countries", Business Process Management Journal, Vol. 7 No. 3, pp. 276284.

Kamhawi, E.M. (2007), "Critical success factors for implementation success of ERP systems: an empirical investigation from Bahrain", International Journal of Enterprise Information Systems, Vol. 3 No. 2, pp. 34-49.

Kamhawi, E.M. (2008), "Enterprise resource-planning systems adoption in Bahrain: motives, benefits, and barriers", Journal of Enterprise Information Management, Vol. 21 No. 3, pp. 310-334.

Kanellis, P. \& Papadopoulos, T. (2008), "Conducting research in information systems", in: A. Cater-Steel \& L. Al-Hakim (Eds), Information Systems Research Methods, Epistemology, and Applications, IGI Press, Hershey, PA, pp. 1-34.

Leavitt, H.J. (1965), "Applying organizational change in industry: structural, technological and humanistic approaches", in J.G. March (Ed.), Handbook of Organizations, Rand McNally, Chicago, IL, pp. 1144-1170.

Lyytinen, K. \& Hirschheim, R. (1987), "Information systems failures: a survey and classification of the empirical literature", Oxford Surveys in Information Technology, Vol. 4, pp. 257-309.

Mabert, V., Soni, A. \& Venkataramanan, M. (2001), "Enterprise resource planning: common myths versus evolving reality", Business Horizons, Vol. 44 No. 3, pp. 69-76.

Markus, M.L. \& Robey, D. (1983), "The organizational validity of management information systems", Human Relations, Vol. 36 No. 3, pp. 203-225.

Mead, R. (1998), International Management: Cross-Cultural Dimensions, $2^{\text {nd }}$ edn, Blackwell, Oxford, UK.

Minahan, T. (1998), "Enterprise resource planning: strategies not included", Purchasing, Vol. 125 No. 1, pp. 112-127. 
Molla, A. \& Bhalla, A. (2006), "Business transformation through ERP: a case study of an Asian company", Journal of Information Technology Case and Application Research, Vol. 8 No. 1, pp. 34-54.

Molla, A. \& Loukis, I. (2005), Success and Failure of ERP Technology Transfer: A Framework For Analyzing Congruence of Host and System Cultures, Development Informatics working paper no. 24, IDPM, University of Manchester, UK, available at: http://www.sed.manchester.ac.uk/idpm/research/publications/wp/di/di_wp24.htm (accessed 28 Jun 2009).

Montealegre, R. (1999), "A case for more case study research in the implementation of information technology in less-developed countries", Information Technology for Development, Vol. 8 No. 4, pp. 199-207.

Muscatello, J.R. \& Parente, D.H. (2006), "Enterprise resource planning (ERP): a postimplementation cross-case analysis", Information Resources Management Journal, Vol. 19 No. 3, pp. 61-80.

Nicolaou, A. (2004), "ERP systems implementation: drivers of post-implementation success", paper presented at the 2004 IFIP International Conference on Decision Support Systems, 1-3 July, Prato, Italy.

Nielsen, J.L. (2002), Critical Success Factors For Implementing An ERP System In A University Environment: A Case Study From The Australian HES, Bachelors thesis, Faculty of Engineering and Information Technology, Griffith University, Queensland, Australia, available at:

http://www.sqi.gu.edu.au/docs/theses/JNielsen_Dissertation_ERP.pdf (accessed 28 Jun 2009).

Orlikowski, W.J. \& Gash, D.C. (1994), "Technological frames: making sense of information technology in organizations", ACM Transactions on Information Systems, Vol. 12 No. 2, pp. 174-207.

Pliskin, N., Romm, T., Lee, A.S. \& Weber, Y. (1993), "Presumed versus actual organizational culture: managerial implications for implementation of information systems", The Computer Journal, Vol. 36 No.2, pp.143-52.

Poulymenakou, A. \& Holmes, A. (1996), "A contingency framework for the investigation of information systems failure", European Journal of Information Systems, Vol. 5, pp. 34-46.

Rajapakse, J., \& Seddon, P. (2005a), Why ERP May Not Be Suitable For Organizations In Developing Countries In Asia, Working paper no.121, Department of Information Systems, University of Melbourne, available at: http://www.pacisnet.org/file/2005/121.pdf (accessed 28 Jun 2009).

Rajapakse, J. \& Seddon, P. (2005b), "ERP adoption in developing countries in Asia: a cultural misfit", paper presented at the 28th Information Systems Seminar in

Scandinavia, 6-9 August, Kirstiansand, Norway, available at:

http://www.hia.no/iris28/Docs/IRIS2028-1028.pdf (accessed 3 Mar 2009). 
Rasmy, M., Tharwat, A. \& Ashraf, S. (2005), "Enterprise resource planning (ERP) implementation in the Egyptian organizational context", paper presented at the European Mediterranean Conference on Information Systems, 7-8 June, Cairo, available at: http://www.iseing.org/emcis/EMCIS2005/pdfs/21.pdf (accessed 28 Jun 2009).

Sarker, S. \& Lee, A.S. (2003), "Using a case study to test the role of three key social enablers in ERP implementation", Information \& Management, Vol. 40 No. 8, pp. 813-829.

Sauer, C. (1999), "Deciding the future for IS failures: not the choice you might think", in R. Galliers \& W.L. Currie (Eds), Rethinking Management Information Systems, Oxford University Press, Oxford, UK, pp. 279-309.

Sbool, A.(2006), Personal interview, Amman, Jordan, 30 May.

Shang, S. \& Seddon, P. (2000), "A comprehensive framework for classifying the benefits of ERP Systems", paper presented at the 2000 Americas Conference on Information Systems, 10-13 August, Long Beach, CA.

Shoib, G. \& Nandhakumar, J. (2003), "Cross-cultural IS adoption in multinational corporation", Information Technology for Development, Vol. 10, pp. 249-260.

Skok, W. \& Döringer, H. (2001), "Potential impact of cultural differences on enterprise resource planning (ERP) projects", Electronic Journal of Information Systems in Developing Countries, Vol. 7 No. 5, pp. 1-8.

Soh, C., Kien, S. \& Tay-Yap, J. (2000), "Cultural fits and misfits: is ERP a universal solution?", Communications of the ACM, Vol. 43 No. 4, pp. 47-51.

Soja, P. (2008), "Difficulties in enterprise system implementation in emerging economies", Information Technology for Development, Vol. 14 No. 1, pp. 31-51.

Stewart, G., Milford, M., Jewels, T., Hunter, T. \& Hunter, B. (2000), "Organizational readiness for ERP implementation", paper presented at the 2000 Americas Conference on Information Systems, 10-13 August, Long Beach, CA.

Suchman, L. (1987), Plans and Situated Actions, Cambridge University Press, Cambridge, UK.

Sumner, M. (2000), "Risk factors in enterprise-wide/ERP projects", Journal of Information Technology, Vol. 15 No. 4, pp. 317-327.

Umble, E. \& Umble, M. (2002), "Avoiding ERP implementation failure", Industrial Management, Vol. 44 No. 1, pp. 25-34.

Venkatraman, N. (1989), "The concept of fit in strategy research", Academy of Management Review, Vol. 14 No. 3, pp. 423-444. 
Walsham, G. (2002), "Cross-cultural software production and use: a structurational analysis", MIS Quarterly, Vol. 26 No. 4), pp. 359-380.

Wang, E.T.G., Lin, C.C.-L., Jiang, J.J. \& Klein, G. (2007), "Improving enterprise resource planning (ERP) fit to organizational process through knowledge transfer", International Journal of Information Management, Vol. 27 No. 3, pp. 200-212.

Wong, A., Scarborough, H. \& Chau, P. (2004), "Examining the ERP implementation process from a failure case", paper presented at the 8th Pacific Asia Conference on Information Systems, 8-11 July, Shanghai, China.

Wu, J.-H. \& Wang, Y.-M. (2007), "Measuring ERP success: the key-users' viewpoint of the ERP to produce a viable IS in the organization", Computers in Human Behavior, Vol. 23 No. 3, pp. 1582-1596.

Xue, Y., Liang, H., Boulton, W.R. \& Snyder, C.A. (2005), "ERP implementation failures in China: case studies with implications for ERP vendors", International Journal of Production Economics, Vol. 97 No. 3, pp. 279-295.

Yin, R.K. (1994), Case Study Research: Design and Methods, $2^{\text {nd }}$ edn., Sage, Thousand Oaks, CA.

Zhang, L., Lee, M., Zhang, Z. \& Banerjee, P. (2002), "Critical success factors of enterprise resource planning systems implementation success in China", paper presented at the 36th Hawaii International Conference on System Sciences, 6-9 January, Hawaii. 